\title{
Serologic monitoring of animal welfare-oriented laying-hen farms in South Korea
}

\author{
Hyunhee So, Seolryung Jeong, Jongsuk Mo, Kyungchul Min, Jongnyeo Kim, In-Pil Mo* \\ College of Veterinary Medicine, Chungbuk National University, Cheongju 28644, Korea
}

(Received: September 21, 2018; Revised: November 27, 2018; Accepted: December 19, 2018)

\begin{abstract}
As animal welfare issue becomes important, the European Union bans conventional cages for laying hens from 2012. So the alternative housing systems like floor pens, aviaries or free range systems have been suggested. From 2011 to 2014, we monitored 20 welfare-oriented laying hen farms in South Korea to figure out serological status of major viral diseases. During this period, total 3,219 blood samples were collected from the randomly selected chickens to test and evaluate the hemagglutination inhibition titers for low pathogenic avian influenza, Newcastle disease and egg drop syndrome '76. A total of 2,926 blood samples were tested through enzyme linked immunosorbent assay (ELISA) to assess the serological status of infectious bronchitis (IB). The distribution of ELISA titers for IB was various from almost 0 to 20,000 through the all weeks of age. Also, the antibody coefficient of variation for most of the diseases in this study was higher than those of typical cage layers. As this study was the first surveillance for major avian viral diseases of the animal welfare-oriented farms in South Korea, the results obtained from this study will help to determine what information and resources are needed to maintain better biosecurity and to improve the health and welfare of laying hen flocks.
\end{abstract}

Keywords: Influenza in birds, Newcastle disease, infectious bronchitis, serology, sentinel surveillance

\section{Introduction}

Good animal welfare requires disease prevention and veterinary treatment, appropriate shelter, management, nutrition, humane handling and humane slaughter/killing. Battery hens are vulnerable to stress and diseases due to spending their time constantly standing on the wire floors designed to facilitate egg collection. The layers kept in the animal-welfare oriented farm can be allowed to express more of their natural behaviors such as perching, dustbathing and nesting [18]. In some countries such as USA and Canada, there is a movement for the layer farms from conventional cage housing systems to enriched cage housing systems or floor kept housing systems, which brings other concerns about the different way of disease management $[9,11,21]$.

The most important infectious viral diseases mainly monitored in the laying hen farms in Korea are Newcastle disease (ND), avian influenza (AI), egg drop syndrome (EDS'76), and infectious bronchitis (IB). Among main viral diseases to be monitored, ND is a devastating worldwide disease of poultry characterized by increased respiration, circulatory disturbances, hemorrhagic enteritis, and nervous signs [22]. Once the vaccination against ND virus is done properly, flocks can be effectively protected by this virus [5, 10]. Low pathogenic AI (LPAI) H9N2 subtype has become endemic in poultry in many of the affected countries. However, these outbreaks have tended to have been overshadowed by the H5N1 Highly pathogenic AI (HPAI) virus [1], because HPAI presents severe signs with histologic lesions and inflammation in the various internal organs that result in high mortality [17]. To control LPAI outbreaks, the Korean veterinary authority has permitted the use of the inactivated oil adjuvant H9N2 LPAI vaccine since 2007 [14, 20]. EDS'76 virus is an important pathogen that causes significant decrease of egg production in the layers. This virus was demonstrated high prevalence in the wild and domestic ducks in South Korea [4]. This virus should be included in the monitoring because it affects layers by developing severe abnormal egg production accompanied by the laying of shell-less, softshelled, and thin-shelled eggs [24]. IB is a highly contagious disease in chickens. Surveillance and identification of IB virus types are extremely important for control of the disease [8]. For surveillance purposes, ELISA is the method of choice, regardless of the antigenic type of IB virus involved [7].

Animal welfare has achieved significant global prominence and this trend may affect public policies, commerce and trade [6]. Despite this movement, there are not so many studies to investigate welfare-oriented farms by routine disease monitoring and environment inspection. The Avian Disease Laboratory, College of Veterinary Medicine, Chungbuk

*Corresponding author

Tel: +82-43-261-3356, Fax: +82-43-261-3224

E-mail: moip@cbu.ac.kr 
National University in Korea conducted serologic monitoring and environment inspection for 20 welfare-oriented farms from 2011 to 2014 . The purpose of this study was to investigate the prevalence and serological status of several important infectious diseases in the flocks kept in the welfareoriented farms.

\section{Materials and Methods}

\section{Outline of investigated farms}

The monitoring was conducted through a total of 82 flocks in the 20 farms engaged with a company called Pulmuone (Korea) from 2011 to 2014. All of the farms had animal welfare-oriented litter floor housing systems with supporting enough natural ventilation and sun-light. Number of the birds kept in floor space per square meter was less than 9. Number of flocks in a farm was between 1 and 5 and average 3,000 birds were kept in a flock. All the housing systems were designed to allow hens to maintain a natural posture throughout.

The basic vaccination program was similar to that of typical cage layers. The diseases in the vaccination program included ND, Marek's disease, infectious bursal disease, LPAI, IB (M41+KM91 strain), avian encephalomyelitis, infectious laryngotracheitis, coccidiosis, Mycoplasma gallisepticum and EDS'76 (Table 1).

\section{Farm monitoring}

Total number of farms in the monitoring conducted from 2011 to 2014 was 20 with 82 flocks. The frequency of taking blood samples from randomly selected birds through the wing vein by visiting the farm for serological surveillance was basically once every 2 months. The main diseases for the serological test were ND, LPAI, EDS' 76 and IB. When the new flock (day-old chicks) arrived, blood samples were collected for evaluation of the level of maternal antibodies, which was conducted for every flock.

\section{Serology}

Whole blood samples for the test were collected from 10 randomly selected layers in each flock. For the evaluation of antibodies against LPAI, ND and EDS'76 virus, haemagglutinin inhibition (HI) test was conducted. Briefly, the sera collected from flocks were added to a U-form 96 microplates
(Greiner Bio-One, Germany) and diluted two fold with phosphate-buffered saline using an auto diluter (Bisteque 203II; Cosmotec, Japan). Four HI unit of antigen was added to all wells and incubated at room temperature for $20 \mathrm{~min}$. The antigens for the test were provided by Animal and Plant Quarantine Agency (Korea). A 25- $\mu \mathrm{L}$ of fresh chicken RBC made from Alserver's solution was then added to each well and the plate was incubated at room temperature for $40 \mathrm{~min}$. After incubation, the plates were read for antibody titers.

For the detection of antibodies to IB virus, enzyme-linked immunosorbent assay (ELISA) was performed by using a commercial ELISA kit provided by IDEXX Laboratories (USA).

The serum titers of each flock were analyzed based on the result of geometric mean titer, SD and coefficient of variation $(\mathrm{CV})$. The results of the titers against each disease were grouped according to the weeks of age. The CV represents the ratio of the SD to the mean. $\mathrm{CV}$ is a standardized measure of dispersion of a probability distribution. All the serological data collected from these animal welfare-oriented farms were compared with the typical serological data of layer sera submitted to Avian Disease Laboratory, College of Veterinary Medicine, Chungbuk National University in Korea.

Table 1. The vaccination program for the animal-welfare layer farms in this study

\begin{tabular}{cll}
\hline \hline Age (d) & \multicolumn{1}{c}{ Vaccine } & Administration method \\
\hline 1 & ND, MD & In-ovo, injection \\
5 & Coccidiosis & Drinking water \\
7 & IBD & Drinking water \\
14 & ND+IB & Drinking water \\
21 & IBD & Drinking water \\
35 & ILT & Eye drop \\
45 & SG & Injection \\
55 & IB, ND, AE & Injection, wing-web \\
75 & ILT+MG & Eye drop \\
100 & LPAI, IB, ND, EDS'76 & Injection \\
\hline
\end{tabular}

ND, Newcastle disease; MD, Marek's disease; IBD, infectious bursal disease; IB, infectious bronchitis; ILT, infectious laryngotracheitis; SG, Salmonella gallinarum, AE, avian encephalomyelitis; MG, Mycoplasma gallisepticum, LPAI, low pathogenic avian influenza; EDS'76, egg drop syndrome '76.

Table 2. Number of blood samples tested for the main viral avian diseases from year 2011 to 2014

\begin{tabular}{lrrrrr}
\hline \hline \multirow{2}{*}{ Diseases } & \multicolumn{3}{c}{ Year } & Total \\
\cline { 2 - 5 } & 2011 & 2012 & 2013 & 2014 & 3,174 \\
ND & 1,028 & 852 & 1,049 & 245 & 3,219 \\
LPAI & 1,047 & 859 & 1,064 & 249 & 2,487 \\
EDS'76 & 741 & 578 & 959 & 209 & 2,926 \\
IB & 905 & 742 & 1,032 & 247 & \\
\hline
\end{tabular}

The reason for the difference of the number of samples between the diseases is because every sample was not used for all of the targeted diseases. 


\section{Results}

The number of blood samples collected from the farms for monitoring during the 4 years was 3,219 which were tested to obtain the level of HI titer for ND, LPAI and EDS' 76 and ELISA titer for IB. The amount of the serological test were 3,174 for ND, 3,219 for LPAI, 2,487 for EDS'76 and 2,926 for IB (Table 2). The serological result obtained from the monitoring carried out from 2011 to 2014 was analyzed by grouping into 5 stages according to the layers' age in weeks.

\section{ND}

The result showed that the HI mean titer $\left(\log _{2}\right)$ of antibody against ND virus varied from 5.4 to 8.3 (Table 3 ). The HI mean titer was lower in $0-10$ weeks of age than the rest of the stages but it was higher than that of typical cage layers (Table 4). Overall titers were stable throughout the 4 years. As compared of the titers in each year, titers in 2014 were higher or similar to those of the other years. The level of titers in 2011 was the lowest than the rest of years and it was lower than that of typical cage layers. The $\mathrm{CV}$ was various from 10.3 to $44.4 \%$ and higher than those of typical cage layers (Table 4) throughout all the weeks and years except at the $0-10$ weeks of age in 2014 .

\section{LPAI}

The LPAI HI titer $\left(\log _{2}\right)$ was obtained by whole blood taken from positive flocks and summarized in Table 5. With regard to the maternal antibody taken from day-old chicks, 18 flocks out of 24 flocks showed positive in the LPAI antibody level, which represents $75 \%$ of the flocks were positive. The result showed that the HI mean titer $\left(\log _{2}\right)$ of antibody against LPAI virus varies from 3.1 to 6.1. The average CV was $35 \%$ which was higher than that of typical cage layers (Table 4). The LPAI HI mean titer was lowest in 2011 and 2012. The mean titer was highest in 2014. Overall mean titers were stable throughout the 4 years. The CV was various from 23.3 to $46.2 \%$ and higher than those of typical cage layers (Table 4) throughout all the weeks and years except at the $41-60$ weeks of age in 2014 .

Table 3. Comparison of hemagglutination inhibition (HI) titer against ND virus monitored for the layer flocks in the animal welfareoriented farms from year 2011 to 2014

\begin{tabular}{cccccc}
\hline \hline \multirow{2}{*}{ Age (wk) } & \multirow{2}{*}{ Number of samples } & \multicolumn{5}{c}{ HI antibody titer* } \\
\cline { 3 - 6 } & & 2011 & 2012 & 2013 & 2014 \\
\hline $0-10$ & 505 & $6.1 \pm 2.3(38.4)$ & $6.2 \pm 1.9(30.9)$ & $5.4 \pm 2.4(44.4)$ & $6.5 \pm 0.7(10.3)$ \\
$11-22$ & 662 & $7.6 \pm 2.0(26.7)$ & $7.4 \pm 1.8(24.7)$ & $7.7 \pm 1.7(22.8)$ & $7.8 \pm 2.2(28.4)$ \\
$23-40$ & 888 & $6.9 \pm 2.4(34.3)$ & $7.3 \pm 1.6(21.3)$ & $7.8 \pm 1.4(17.9)$ & $8.2 \pm 1.3(15.7)$ \\
$41-60$ & 832 & $7.5 \pm 1.2(16.1)$ & $7.2 \pm 1.7(23.1)$ & $7.6 \pm 1.4(18.5)$ & $7.5 \pm 1.6(21.8)$ \\
$>60$ & 287 & $7.3 \pm 1.9(25.6)$ & $7.3 \pm 1.3(18.1)$ & $7.2 \pm 1.7(24.1)$ & $8.3 \pm 1.2(14.0)$ \\
\hline
\end{tabular}

*Geometric mean titer \pm SD (coefficient of variation, \%).

Table 4. Reference table from a study on serological results against major viral diseases for caged layer flocks [15]

\begin{tabular}{|c|c|c|c|c|c|c|c|}
\hline \multirow{2}{*}{ Diseases } & \multicolumn{7}{|c|}{ Antibody titer* } \\
\hline & $0-1.5^{\dagger}$ & $1.5-3$ & $3-10$ & $10-22$ & $22-40$ & $40-60$ & $>60$ \\
\hline AI & $\begin{array}{c}1.3 \pm 0.5 \\
(47.4)\end{array}$ & $\begin{array}{l}0.9 \pm 0.4 \\
(18.6)\end{array}$ & $\begin{array}{l}0.5 \pm 0.2 \\
(4.2)\end{array}$ & $\begin{array}{l}2.4 \pm 0.6 \\
(20.5)\end{array}$ & $\begin{array}{c}4.0 \pm 0.9 \\
(22.6)\end{array}$ & $\begin{array}{l}3.4 \pm 0.9 \\
(27.0)\end{array}$ & $\begin{array}{c}3.7 \pm 1.0 \\
(36.6)\end{array}$ \\
\hline ND & $\begin{array}{c}6.1 \pm 0.9 \\
(14.9)\end{array}$ & $\begin{array}{l}4.1 \pm 1.0 \\
(24.8)\end{array}$ & $\begin{array}{l}5.5 \pm 1.3 \\
(23.1)\end{array}$ & $\begin{array}{l}7.5 \pm 1.0 \\
(13.2)\end{array}$ & $\begin{array}{c}8.1 \pm 1.0 \\
(13.0)\end{array}$ & $\begin{array}{l}7.7 \pm 0.9 \\
(12.2)\end{array}$ & $\begin{array}{c}7.9 \pm 0.9 \\
(11.3)\end{array}$ \\
\hline IB & $\begin{array}{c}3,985 \pm 2,403 \\
(41.5)\end{array}$ & $\begin{array}{c}1,207 \pm 1,180 \\
(60.3)\end{array}$ & $\begin{array}{c}1,181 \pm 847 \\
(53.4)\end{array}$ & $\begin{array}{c}5,051 \pm 1,855 \\
(41.5)\end{array}$ & $\begin{array}{c}6,738 \pm 2,095 \\
(31.3)\end{array}$ & $\begin{array}{l}6,696 \pm 2,120 \\
(31.5)\end{array}$ & $\begin{array}{c}6,682 \pm 2,266 \\
(34.0)\end{array}$ \\
\hline EDS'76 & NT & NT & NT & $\begin{array}{l}4.1 \pm 1.1 \\
(26.0)\end{array}$ & $\begin{array}{c}4.6 \pm 0.9 \\
(20.0)\end{array}$ & $\begin{array}{c}2.9 \pm 0.9 \\
(30.8)\end{array}$ & $\begin{array}{l}5.1 \pm 1.4 \\
(25.3)\end{array}$ \\
\hline aMPV & NT & NT & $\begin{array}{l}128 \pm 216 \\
(144)\end{array}$ & $\begin{array}{c}1,687 \pm 1,871 \\
(102)\end{array}$ & $\begin{array}{c}1,861 \pm 2,947 \\
(89.0)\end{array}$ & $\begin{array}{c}7,253 \pm 4,971 \\
(67.0)\end{array}$ & $\begin{array}{c}4,727 \pm 5,864 \\
(96.0)\end{array}$ \\
\hline IBD & $\begin{array}{c}4,282 \pm 2,231 \\
(36,9)\end{array}$ & NT & $\begin{array}{c}1,010 \pm 487 \\
(43.2)\end{array}$ & $\begin{array}{c}7,299 \pm 1,707 \\
(20.0)\end{array}$ & $\begin{array}{c}8,890 \pm 1,374 \\
(15.1)\end{array}$ & $\begin{array}{c}6,898 \pm 182 \\
(24.6)\end{array}$ & $\begin{array}{c}6,730 \pm 1,686 \\
(24.2)\end{array}$ \\
\hline CIA & $\begin{array}{c}1.19 \pm 0.10 \\
(8.64)\end{array}$ & $\begin{array}{c}1.05 \pm 0.09 \\
(9.11)\end{array}$ & $\begin{array}{l}0.14 \pm 0.13 \\
\quad(72.1)\end{array}$ & $\begin{array}{c}0.43 \pm 0.19 \\
(65.8)\end{array}$ & $\begin{array}{c}0.56 \pm 0.57 \\
(68.3)\end{array}$ & $\begin{array}{c}0.36 \pm 0.22 \\
(99.8)\end{array}$ & NT \\
\hline
\end{tabular}

AI, avian influenza; aMPV, avian metapneumovirus infection; CIA, chicken infectious anemia; NT, not tested. *Geometric mean titer \pm SD (coefficient of variation, \%). †The age range (in weeks). 
Table 5. Comparison of HI titer against H9N2 avian influenza virus monitored for the layer flocks in the animal welfare-oriented farms from year 2011 to 2014

\begin{tabular}{cccccc}
\hline \hline \multirow{2}{*}{ Age (wk) } & \multirow{2}{*}{$\begin{array}{c}\text { Number } \\
\text { of samples }\end{array}$} & 2011 & 2012 & 2013 & 2014 \\
\cline { 3 - 6 } & 322 & $3.2 \pm 1.1(33.5)$ & $3.2 \pm 1.5(46.2)$ & $4.1 \pm 1.2(29.8)$ & $4.8 \pm 1.7(34.6)$ \\
\hline $0-10$ & 377 & $4.6 \pm 1.5(32.3)$ & $4.8 \pm 1.7(34.6)$ & $5.2 \pm 1.7(33.4)$ & $6.1 \pm 1.9(31.6)$ \\
$11-22$ & 238 & $4.5 \pm 1.8(39.1)$ & $4.1 \pm 1.3(31.6)$ & $4.9 \pm 1.8(36.1)$ & $4.2 \pm 1.0(24.0)$ \\
$23-40$ & 479 & $3.2 \pm 1.4(45.4)$ & $3.9 \pm 1.6(41.0)$ & $4.1 \pm 1.5(36.4)$ & $4.5 \pm 1.1(23.3)$ \\
$41-60$ & 125 & $4.2 \pm 1.1(25.6)$ & $3.1 \pm 1.2(39.4)$ & $4.0 \pm 2.1(53.0)$ & $3.9 \pm 1.2(29.9)$ \\
$>60$ & & &
\end{tabular}

$*$ Geometric mean titer \pm SD (coefficient of variation, \%).

Table 6. Comparison of HI antibody titer against EDS'76 virus monitored for the layer flocks in the animal welfare-oriented farms from year 2011 to 2014

\begin{tabular}{cccccc}
\hline \hline \multirow{2}{*}{ Age (wk) } & \multirow{2}{*}{$\begin{array}{c}\text { Number } \\
\text { of samples }\end{array}$} & 2011 & 2012 & 2013 & 2014 \\
\cline { 3 - 6 } & 382 & $6.0 \pm 2.2(36.8)$ & $6.5 \pm 1.2(19.0)$ & $5.6 \pm 1.9(34.1)$ & $5.6 \pm 2.2(38.9)$ \\
$11-22$ & 726 & $4.9 \pm 2.0(40.4)$ & $5.9 \pm 1.6(27.2)$ & $6.2 \pm 1.8(28.1)$ & $5.1 \pm 1.3(25.7)$ \\
$23-40$ & 712 & $4.4 \pm 1.7(39.3)$ & $5.9 \pm 1.5(25.6)$ & $5.7 \pm 1.7(30.4)$ & $5.3 \pm 1.8(34.6)$ \\
$41-60$ & 260 & $4.8 \pm 2.1(43.6)$ & $6.1 \pm 1.8(29.2)$ & $5.8 \pm 1.6(26.7)$ & $4.4 \pm 2.4(53.5)$ \\
$>60$ & &
\end{tabular}

*Geometric mean titer \pm SD (coefficient of variation, \%).

Table 7. Comparison of enzyme-linked immunosorbent assay (ELISA) antibody titer against IB virus monitored for the layer flocks in the animal welfare-oriented farms from year 2011 to 2014

\begin{tabular}{cccccc}
\hline \hline \multirow{2}{*}{ Age (wk) } & \multirow{2}{*}{$\begin{array}{c}\text { Number } \\
\text { of samples }\end{array}$} & \multicolumn{4}{c}{ ELISA antibody titer* } \\
\cline { 3 - 6 } & & 2011 & 2012 & 2013 & 2014 \\
\hline $0-10$ & 199 & $2,994 \pm 3,220(107.6)$ & $1,110 \pm 995(89.6)$ & $1,175 \pm 1,004(85.4)$ & $359 \pm 127(35.4)$ \\
$11-22$ & 674 & $3,092 \pm 2,371(76.7)$ & $5,326 \pm 4,344(81.6)$ & $3,933 \pm 2,683(68.2)$ & $4,010 \pm 2,416(60.2)$ \\
$23-40$ & 903 & $5,981 \pm 3,236(54.1)$ & $6,157 \pm 3,185(51.7)$ & $4,498 \pm 2,371(52.7)$ & $4,719 \pm 2,249(47.7)$ \\
$41-60$ & 853 & $5,132 \pm 2,540(49.5)$ & $5,361 \pm 3,331(62.1)$ & $4,525 \pm 2,553(56.4)$ & $5,664 \pm 2,821(49.8)$ \\
$>60$ & 297 & $5,224 \pm 2,929(56.1)$ & $8,620 \pm 3,946(45.8)$ & $4,870 \pm 2,381(48.9)$ & $5,595 \pm 2,532(45.3)$ \\
\hline
\end{tabular}

$*$ Geometric mean titer \pm SD (coefficient of variation, \%).

\section{EDS'76}

The EDS'76 HI titer $\left(\log _{2}\right)$ was obtained by whole blood taken from positive flocks and summarized in Table 6. The result showed that the HI mean titer $\left(\log _{2}\right)$ of antibody against EDS'76 virus varied from 4.4 to 6.5 . The average $\mathrm{CV}$ was $32.5 \%$ which was higher than that of typical cage layers (Table 4). Overall mean titers were stable throughout the 4 years. The EDS'76 HI mean titer was lowest in 2011. The mean titers of animal welfare-oriented farm flocks from 2012 to 2014 were generally higher than those of typical cage layers (Table 4). The CV was various from 19.0 to $43.6 \%$ and generally higher than those of typical layers (Table 4) throughout all the weeks and years.

\section{IB}

The serological result showed that the ELISA mean titer of antibody against IB virus varies from 359 to 8,620 (Table 7).
The ELISA mean titer was relatively lower in $0-10$ weeks of age than the rest of the stages. Overall titers were stable throughout the 4 years except in 11-22 weeks of age in 2013. Compared with the titers of typical cage layers (Table 4), level of titers was generally lower in animal welfare-oriented farm layers. The level of titers in 2013 was the lowest than the rest of years and it was lower than that of typical cage layers (Table 4). The CV was various from 35.4 to $107.6 \%$ and higher than those of typical layers throughout all the weeks and years except at the $0-10$ weeks of age in 2014 .

The level of ELISA titers of antibodies against IB virus varied from 0 to 20,000 in every week of age. Suspicious field infection was determined when the level of the titer was over 10,000 and confirmation of filed infection was determined when the level of the titer was over 12,000 in the flock (Fig. 1). 


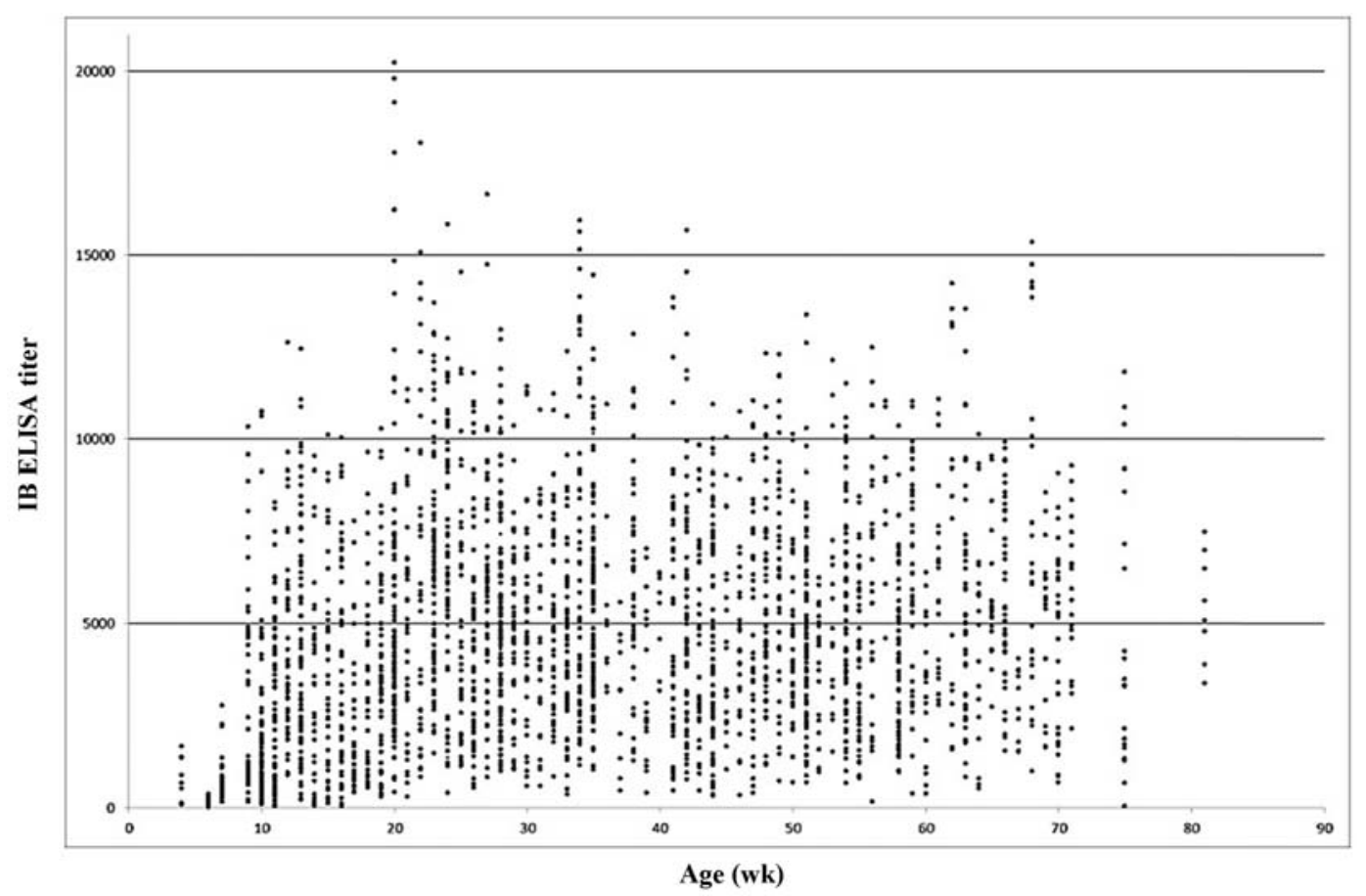

Fig. 1. Distribution of ELISA titers of the specific antibodies against IB virus in individual birds of the layer flocks in the animal welfare-oriented farms from 2011 to 2014.

Table 8. Comparison of maternal antibodies level of AI (H9N2) and ND monitored for day-old flocks in the animal welfare-oriented farms collected from year 2011 to 2014

\begin{tabular}{|c|c|c|c|c|c|c|}
\hline & Year & 2011 & 2012 & 2013 & 2014 & Total \\
\hline \multirow[b]{2}{*}{ AI (H9N2) } & Number of sample & 75 & 60 & 30 & 5 & 170 \\
\hline & Antibody titer* & $\begin{array}{c}3.2 \pm 1.2 \\
\quad(36.7)\end{array}$ & $\begin{array}{c}2.8 \pm 1.3 \\
\quad(46.9)\end{array}$ & $\begin{array}{c}3.2 \pm 1.0 \\
(31.7)\end{array}$ & $\begin{array}{c}5.4 \pm 0.5 \\
\quad(9.1)\end{array}$ & $\begin{array}{c}3.1 \pm 1.3 \\
(40.5)\end{array}$ \\
\hline \multirow[b]{2}{*}{ ND } & Number of sample & 64 & 117 & 30 & 5 & 216 \\
\hline & Antibody titer* & $\begin{array}{l}6.6 \pm 1.5 \\
(22.4)\end{array}$ & $\begin{array}{c}6.4 \pm 1.1 \\
(16.8)\end{array}$ & $\begin{array}{c}7.4 \pm 1.2 \\
(16.2)\end{array}$ & $\begin{array}{l}6.8 \pm 0.4 \\
(5.9)\end{array}$ & $\begin{array}{c}6.6 \pm 1.3 \\
(19.1)\end{array}$ \\
\hline
\end{tabular}

*Geometric mean titer \pm SD (coefficient of variation, \%).

\section{Level of maternal antibodies}

Maternal antibodies for LPAI and ND were evaluated by HI test through whole blood samples taken from the chicks as soon as a flock of day-old chicks arrived in the farm (Table 8). In case of LPAI, positive flocks and negative flocks were sorted according to the presence of maternal antibodies and the mean HI titer against LPAI virus was evaluated only through positive flocks. A total of 75 percent of the day-old flocks were LPAI maternal antibody positive and the geometric mean titer was lowest in year 2012 with the value of 2.8 and highest in 2014 with the value of 5.4. The mean titer was 3.1 when all the samples of day-old chicks were taken into account throughout the 4 years. The mean titer of maternal antibody against ND was lowest with the value of 6.4 in 2012 and highest with the value of 7.4 in 2013. The mean titer was 6.6 when all the samples of dayold chicks throughout the 4 years were evaluated.

\section{Discussion}

Because of the difference of housing systems, it has to be considered to develop biosecurity programs that can be applicable to animal welfare-oriented farms. Serological surveillance and environmental assessment through routine monitoring will contribute to generate a multidimensional picture that can better inform disease prevention and control programs [19]. Therefore, the objective of this study was to assess the serological status of major viral diseases and to evaluate vaccination protocol and sanitary management dedicated to the animal welfare-oriented farms.

In the beginning of this study, the geometric mean titer of antibodies to the selected diseases (ND and LPAI) was lower and the CV was higher (Tables 3 and 5) than the result obtained from the serological surveillance conducted in 2014 the last year of this study. The higher the CV, the greater the 
level of dispersion around the mean titer, so when the value of $\mathrm{CV}$ is lower, then we can estimate the titer is more stable. The reason for this improvement can be explained that the farmers' willingness to understand vaccination program and importance of biosecurity was motivated by education during the performance of monitoring.

The result of this study showed that the CV of the titers to the selected virus tended to be higher than those of typical cage layers. In case of ND, the CV was higher in every week of age post vaccination (inactivated vaccine) throughout the 4 years than that of typical cage layers (Tables 3 and 4). In case of LPAI, the CV was higher in every week of age except at the 41-60 weeks in 2014 than that of typical cage layers (Tables 4 and 5). In case of EDS'76, the CV was higher in almost every week of age except at the 10-22 weeks and 41-60 weeks in 2012 (Tables 4 and 6). In case of $\mathrm{IB}$, the CV was higher in every week of age except the $0-10$ weeks in 2014 than that of typical cage layers (Tables 4 and 7). The reason for this can be explained by the improper vaccination due to the poor condition in working in the farms with welfare-oriented systems [25], therefore it is suggested to emphasize that the workers have to be cautious when they perform vaccination in the welfare-oriented farms.

With regard to LPAI, some flocks took inactivated LPAI vaccination showed the level of LPAI titers since the Korean veterinary authority has permitted the use of the inactivated oil adjuvant H9N2 LPAI vaccine from 2007. However, 11\% of the flocks (4 out of 36 flocks in 2011) during the monitoring turned out to be infected with field LPAI virus through the serological test, which resulted in including LPAI vaccination for every flock in the vaccination program then no LPAI field infection was confirmed through the serological test in 2012 while the 2 cases of LPAI were confirmed by necropsy. Considering studies showed and suggested that the genetic divergence is still occurring hence the long-term H9N2 AIV surveillance study should be continued in South Korea [12] and implementation of the H9N2 vaccination program in Korea has dramatically reduced the diversity of H9N2 virus [13].

IB is a highly contagious viral disease of chickens with a worldwide distribution [3]. The result of the distribution of ELISA titers showed that the titers were variable from almost 0 to 20,000 and the $\mathrm{CV}$ was higher than that of typical layers throughout the monitored period. Despite the possibility that the effectiveness of vaccination can be diminished by poor cross-protection [2], the only practical means of controlling IB is vaccination. The selection of an appropriate antigenic type for the region is important to give the existence of wide antigenic variation [7]. Timing and method of vaccine application may vary for different flocks and may require adjustment according to practical experiences. In spite of extensive vaccination, IB is still epidemic in Korea due to the continual emergency of variants [16].

Currently, the number of studies for assessment of animal welfare-oriented farms through serological monitoring and environmental inspection is limited. In this study, various results are shown through the monitoring conducted over the 4 years. Conventional cages have been outlawed in Europe since 2012 and the move away from keeping hens in conventional battery cages is extending beyond Europe to countries such as Australia, New Zealand, Canada and the USA [23]. This movement will affect other Asian countries including South Korea because the interest in animal welfare becomes a global phenomenon, which will lead to find alternative housing systems for the layers. Through this study, it is expected to contribute to figure out the current status of antibodies to the major viral diseases for developing better biosecurity programs in the future dedicated to the alternative housing systems for animal welfare. Furthermore, more studies are expected to be carried out in a various places in terms of the disease point of view for the animal welfare-oriented farms.

\section{Acknowledgments}

This work was supported by Korea Institute of Planning and Evaluation for Technology in Food, Agriculture, Forestry and Fisheries (IPET) through Animal Disease Management Technology Development Program, funded by Ministry of Agriculture, Food and Rural Affairs (MAFRA) (31604703), Republic of Korea.

\section{References}

1. Alexander DJ. An overview of the epidemiology of avian influenza. Vaccine 2007, 25, 5637-5644.

2. Cavanagh D. Coronavirus avian infectious bronchitis virus. Vet Res 2007, 38, 281-297.

3. Cavanagh D, Naqi S. Infectious bronchitis. In: Saif YM, Barnes HJ, Glisson JR, Fadly AM, McDougald LR, Swayne DE (eds.). Diseases of Poultry. 11th ed. pp. 101-119, Blackwell, Ames, 2003.

4. Cha SY, Kang M, Moon OK, Park CK, Jang HK. Respiratory disease due to current egg drop syndrome virus in Pekin ducks. Vet Microbiol 2013, 165, 305-311.

5. Cho SH, Kwon HJ, Kim TE, Kim JH, Yoo HS, Park MH, Park YH, Kim SJ. Characterization of a recombinant Newcastle disease virus vaccine strain. Clin Vaccine Immunol 2008, 15, 1572-1579.

6. Fraser D. The globalisation of farm animal welfare. Rev Sci Tech 2014, 33, 33-38.

7. Ignjatović J, Sapats S. Avian infectious bronchitis virus. Rev Sci Tech 2000, 19, 493-508.

8. Jackwood MW. Review of infectious bronchitis virus around the world. Avian Dis 2012, 56, 634-641.

9. Janczak AM, Riber AB. Review of rearing-related factors affecting the welfare of laying hens. Poult Sci 2015, 94, 1454-1469.

10. Jeon WJ, Lee EK, Lee YJ, Jeong OM, Kim YJ, Kwon JH, Choi KS. Protective efficacy of commercial inactivated Newcastle disease virus vaccines in chickens against a recent Korean epizootic strain. J Vet Sci 2008, 9, 295-300.

11. Kajlich AS, Shivaprasad HL, Trampel DW, Hill AE, 
Parsons RL, Millman ST, Mench JA. Incidence, severity, and welfare implications of lesions observed postmortem in laying hens from commercial noncage farms in California and Iowa. Avian Dis 2016, 60, 8-15.

12. Lee CH, Byun SH, Lee YJ, Mo IP. Genetic evolution of the H9N2 avian influenza virus in Korean poultry farms. Virus Genes 2012, 45, 38-47.

13. Lee DH, Fusaro A, Song CS, Suarez DL Swayne DE. Poultry vaccination directed evolution of H9N2 low pathogenicity avian influenza viruses in Korea. Virology 2016, 488, 225-231.

14. Lee DH, Song CS. H9N2 avian influenza virus in Korea: evolution and vaccination. Clin Exp Vaccine Res 2013, 2, 26-33.

15. Lee HR, Kim JM, Kim JH, Kim CM, So HH, Lee DW, Ha BD, Hong SC, Mo IP. [Serological survey for the major viral diseases in the layers]. Korean J Poult Sci 2010, 37, 361-372. Korean.

16. Lim TH, Kim MS, Jang JH, Lee DH, Park JK, Youn HN, Lee JB, Park SY, Choi IS, Song CS. Live attenuated nephropathogenic infectious bronchitis virus vaccine provides broad cross protection against new variant strains. Poult Sci 2012, 91, 89-94.

17. Mo IP, Brugh M, Fletcher OJ, Rowland GN, Swayne DE. Comparative pathology of chickens experimentally inoculated with avian influenza viruses of low and high pathogenicity. Avian Dis 1997, 41, 125-136.

18. Moesta A, Briese A, Knierim U, Hartung J. [Behaviour of laying hens in aviaries-review. Part 2: Feeding behaviour, reproductive and dust bathing behaviour of chickens]. Dtsch
Tierarztl Wochenschr 2008, 115, 4-14. German.

19. Parmley EJ, Pintar K, Majowicz S, Avery B, Cook A, Jokinen C, Gannon V, Lapen DR, Topp E, Edge TA, Gilmour M, Pollari F, Reid-Smith R, Irwin R. A Canadian application of one health: integration of Salmonella data from various Canadian surveillance programs (20052010). Foodborne Pathog Dis 2013, 10, 747-756.

20. Shin JH, Mo JS, Kim JN, Mo IP, Ha BD. Assessment of the safety and efficacy of low pathogenic avian influenza (H9N2) virus in inactivated oil emulsion vaccine in laying hens. J Vet Sci 2016, 17, 27-34.

21. van Staaveren N, Decina C, Bases CF, Widowski TM, Berke O, Harlander-Matauschek A. A description of laying hen husbandry and management proctices in Canada. Animals (Basel) 2018, 8, 114.

22. Wang JY, Liu WH, Ren JJ, Tang P, Wu N, Wu HY, Ching CD, Liu HJ. Characterization of emerging Newcastle disease virus isolates in China. Virol J 2015, 12, 119.

23. Weeks CA, Lambton SL, Williams AG. Implications for welfare, productivity and sustainability of the variation in reported levels of mortality for laying hen flocks kept in different housing systems: a meta-analysis of ten studies. PLoS One 2016, 11, e0146394.

24. Yamaguchi S, Imada T, Kawamura H, Taniguchi S, Saio H, Shimamatsu K. Outbreaks of egg-drop syndrome-1976 in Japan and its etiological agent. Avian Dis 1981, 25, 628-641.

25. Zhao Y, Shepherd TA, Li H, Xin H. Environmental assessment of three egg production systems-Part I: Monitoring system and indoor air quality. Poult Sci, 2015, 94, 518-533. 